\title{
Impact of Health Education on the Knowledge and Practice Regarding Personal Hygiene among Primary School Children in Urban Area of Karnataka, India
}

\author{
Ashutosh Shrestha ${ }^{1}$, Mubashir Angolkar ${ }^{2}$ \\ ${ }^{1}$ P.G student, MPH, Department of Public Health, J.N. Medical College, KLE University, Belgaum, India. \\ ${ }^{2}$ Assistant Professor, BDS, MsC, PhD, Coordinator of Department of Public Health, J. N. Medical College, \\ KLE University, Belgaum, India
}

\begin{abstract}
Introduction: Poor personal hygiene, in combination with insanitary conditions and contaminated water, creates a serious public health threat to school children. Children are not conscious of personal hygiene at school level. For better knowledge health education is needed. Objective: To assess the change on knowledge and practice regarding personal hygiene among primary school children after educational interventions. Material and methods: Out of 7 schools Government Urdu Primary School was selected by Simple Random Sampling. All of students of grade $3^{\text {rd }}, 4^{\text {th }}$ and $5^{\text {th }}$ were included. Baseline and end line survey was done in February and September 2013. Health education sessions were conducted once a week for six weeks. Paired $t$ test, Mc Nemar test and proportions were calculated. Ethical clearance and informed consent was obtained. Results: The mean knowledge score of personal hygiene increased from 51.55 to 75.46 which was statistically significant at paired t 13.01, df 19 and $p<0.01$. The mean practice score of personal hygiene increased from 44.19 to 69.22 which was statistically significant at paired $t 7.26$, df 8 and $p<0.01$. Conclusion: There is need of proper health education intervention through framework of schools to the school children, for improvement regarding personal hygiene among them, throughout the nation.
\end{abstract}

Keywords: Personal hygiene, Sanitation, Health Education, School Children

\section{Introduction}

Poor personal hygiene, in combination with insanitary conditions and contaminated water, creates a serious public health threat to school children. Globally, 2.5 billion people had inadequate sanitation facilities and living with poor personal hygiene. ${ }^{1}$ There are nearly 7 lakhs primary schools in India. Out of them only half has safe drinking water facility and only $10 \%$ have sanitary facilities. Due to lack private and decent sanitation facilities at schools many children had low personal hygiene and increased burden of diseases. ${ }^{1,2}$ Poor personal hygiene is related to nutrition deficiencies, worm infestations and diarrhea. It adversely affects the attendance at school and learning process. ${ }^{3}$

Due to inadequate sanitary conditions and poor personal hygiene practices, the increasing burden of communicable diseases among school children remains a concern on the public health agenda in developing countries. ${ }^{4}$ Children are not conscious of personal hygiene at school level. Majority of the schools are not fenced allowing the domestic animals to step around the school premises, making children vulnerable to many zoonotic infections. Feet and hands of children playing at such ground with animal dong get contaminated and eventually contaminate their friends and the classroom. In this way the school environment becomes a reservoir for many kinds of health hazards due to poor personal hygiene. ${ }^{5}$

For the better knowledge and practice, the health education intervention program was very much fruitful to the growing children for their better health and upcoming future. So, this study was undertaken to know the impact of health education on the knowledge and practice regarding personal hygiene among primary school children in urban area.

\section{Material And Methods}

This was a pre and post test study design, conducted at Government Urdu Primary School, New Veer Bhadra Nagar under Ramnagar Urban Health Center (UHC), Belgaum. Out of seven schools Government Urdu Primary School was selected by simple random sampling. All 96 students studying at 3rd, 4th and 5th standard were included under this study. Baseline survey was done in February 2013 and end line survey was done in September 2013. Health education was given once a week from May to June 2013 for five groups in which four groups had 19 students and remaining one group had 20 students. The package was for 6 days, 45 min each day and it included variables of personal hygiene, hand hygiene, oral hygiene and basic sanitation. Pilot study was conducted among 10 percent of students and there was no major correction in the questionnaire. So, these students were included in the main study. 
A pilot tested questionnaire was used to collect the data. Student willing to participate were included and students who did not attended health education session were excluded from the study. Ethical clearance was obtained from the Institutional Ethics Committee of the JNMC, KLE University. The conduct of the study and the management of the data confirmed to the University's requirements.

All individuals who participated in this study received verbal and written explanation of the procedures involved and the benefits expected from the study. Written consent was obtained from the school principal and respective class teachers before the initiation of the study. Assent was from each of the participant. Paired t test and Mcnemar test were used to see the association between pre and post test variables. These data were entered and analyzed into SPSS software (SPSS 20.0 Version). Mean, proportions and percentages were also calculated.

\section{Results}

The present study comprised of total 96 students, 27(28.1\%) were male and 69(71.9\%) were female. With regard to age distribution, 44(45.8\%) are in 8-10 years age group in which $13(29.5 \%)$ were male and $31(70.5 \%)$ were female. There were 52(54.2\%) children in $11-13$ years age group, among them $14(26.9 \%)$ were male and $38(73.1 \%)$ were female.

Table I showed that the mean knowledge score of personal hygiene was 51.55 which increased to 75.46 after health education intervention, which was statistically significant at paired t 13.01 , df 19 and $\mathrm{p}<0.01$. The mean practice score of personal hygiene was 44.19 which increased to 69.22 after health education intervention. The increase in correct practice was statistically significant at paired t 7.26, df 8 , and $\mathrm{p}<0.05$.

Table I: Mean knowledge and practice score before and after health education intervention.

\begin{tabular}{|l|l|l|l|l|l|}
\hline Score & $\begin{array}{l}\text { Before } \\
\text { Intervention }\end{array}$ & After Interventtion & Mean difference \pm SD & Paired t & P value \\
\hline Knowledge & 51.55 & 75.46 & $23.91 \pm 2.91$ & 13.01 & $<0.01^{*}$ \\
\hline Practice & 44.19 & 69.22 & $25.03 \pm 2.42$ & 7.26 & $<0.05^{*}$ \\
\hline \multicolumn{4}{|l|}{ *significant at p<0.05 } \\
\hline
\end{tabular}

Table II demonstrated the knowledge on personal hygiene, hand washing before and after defecation, use of soap in hand washing, brushing twice daily, tooth decay, nail cutting and sanitation increased after health education intervention and were statistically significant at $\mathrm{p}<0.05$.

The knowledge about bathing and eye hygiene increased but was not statistically significant.

Table II: Knowledge among students before and after health education intervention.

\begin{tabular}{|c|c|c|c|c|}
\hline Knowledge & Before Intervention (\%) & After Intervention (\%) & McNemar $\chi^{2}$ & P value \\
\hline Personal hygiene & $22(22.9)$ & $48(50)$ & 5.123 & $<0.05^{*}$ \\
\hline $\begin{array}{l}\text { Hand wash before } \\
\text { eating }\end{array}$ & $82(85.4)$ & $95(99)$ & 58.715 & $<0.001^{*}$ \\
\hline $\begin{array}{l}\text { Using soap to wash } \\
\text { hands before eating }\end{array}$ & $37(45.12)$ & $67(70.52)$ & 3.93 & $<0.05^{*}$ \\
\hline $\begin{array}{l}\text { Hand wash after } \\
\text { going to toilet }\end{array}$ & $53(55.2)$ & $86(89.6)$ & 13.624 & $<0.001^{*}$ \\
\hline $\begin{array}{l}\text { Using soap to wash } \\
\text { hands after going to } \\
\text { toilet }\end{array}$ & $53(55.2)$ & $86(89.6)$ & 13.624 & $<0.001^{*}$ \\
\hline Bathing & $46(47.92)$ & $63(65.62)$ & 1.27 & 0.254 \\
\hline Brushing twice a day & $80(83.33)$ & $92(95.8)$ & 52.083 & $<0.001^{*}$ \\
\hline Tooth decay & $71(74)$ & $88(91.7)$ & 15.611 & $<0.001 *$ \\
\hline Nail cutting & $80(83.33)$ & $93(96.9)$ & 52.991 & $<0.001 *$ \\
\hline Eye hygiene & $37(38.5)$ & $67(69.8)$ & 0.389 & 0.533 \\
\hline Sanitation & $70(72.92)$ & 93(96.86) & 36.605 & $<0.001^{*}$ \\
\hline \multicolumn{5}{|c|}{ *significant at $\mathrm{p}<0.05$} \\
\hline
\end{tabular}

Table III showed that the correct six steps of hand washing, clean body, brushing steps, oral hygiene, nail cutting and clean uniform increased after health education intervention and was statistically significant at $\mathrm{p}<0.05$. 
The practice of hand hygiene and hair cut among boys increased, but was not statistically significant.

Table III: Practice among students before and after health education intervention.

\begin{tabular}{|l|l|l|l|l|}
\hline Practice & Before Intervention (\%) & After Intervention (\%) & McNemar $\chi^{2}$ & P value \\
\hline $\begin{array}{l}\text { Six steps of hand } \\
\text { washing }\end{array}$ & 0 & $34(35.4)$ & 31.529 & $<0.001 *$ \\
\hline Hand hygiene & $44(45.8)$ & & & \\
\hline Clean body & $64(66.67)$ & $62(64.6)$ & 0.711 & 0.399 \\
\hline Brushing steps & 0 & $80(83.33)$ & 19.723 & $<0.001 *$ \\
\hline Oral hygiene & $55(57.3)$ & $69(35.4)$ & 31.529 & $<0.001 *$ \\
\hline Nail cutting & $49(51)$ & $80(83.33)$ & 31.529 & $<0.05^{*}$ \\
\hline Clean uniform & $73(76)$ & $81(84.4)$ & 8.062 & $<0.05 *$ \\
\hline Hair cut among boys & $16(59.25)$ & $22(81.48)$ & 31.24 & $<0.001 *$ \\
\hline & & & 3.03 & 0.082 \\
\hline
\end{tabular}

\section{Discussion}

In our study, there was significant increase in knowledge and practice score of school children after health education intervention $(\mathrm{p}<0.05)$ which was supported by the study conducted by Siwach M. They reported significant increase in knowledge and practice after health education intervention in Panipat, India. ${ }^{6}$ Similarly, study conducted by IIika AL et al in Nigeria found significant change in personal hygiene practice. ${ }^{7}$

In the present study the knowledge about personal hygiene increased after health education intervention and was statistically significant $(\mathrm{p}<0.05)$. The findings were similar to the study conducted by Greene LE et al in Western Kenya where increase in knowledge was statistically significant after intervention. ${ }^{8}$

The present study showed that hand washing practice before and after defecation increased significantly $(p<0.05)$. The knowledge of using soap for washing hands also significantly increased $(p<0.05)$. Our findings were supported by the studies conducted at national and international level. Our findings were similar to the findings of Schmidt et al findings in East London, $\mathrm{UK}^{9}$, White $\mathrm{C}$ et al in Colorado USA where hand washing increased significantly in control group ${ }^{10}$, Greene LE et al findings that reported increase in use of soap for washing hands before eating and after defecation in Western Kenya and was statistically significant. ${ }^{8}$ Our findings were similar to the study conducted by Aiello AE et al in USA where hand washing knowledge increased ${ }^{11}$, Reilly CEO et al in Western Kenya where hand washing knowledge increased and was statistically significant ${ }^{12}$, Riaz M et al behaviour intervention in Bangladesh showed increase in knowledge about hand hygiene and was statistically significant. ${ }^{13}$

In our study the knowledge about brushing increased and was statistically significant $(\mathrm{p}<0.001)$. The findings of our study were supported by the studies conducted by Lee A et al where tooth brushing knowledge increased and was statistically significant at health education intervention schools in Hong Kong ${ }^{14}$, study conducted by Siwach M in Panipat, India where tooth brushing knowledge increase was statistically significant 15, study conducted Dongre AR et al in Maharashtra, India reported that concept of clean teeth increased significantly. ${ }^{16}$

The present study revealed that knowledge about tooth decay significantly increased after health education intervention $(\mathrm{P}<0.001)$. Our findings were similar to the study conducted by Amol $\mathrm{R}$ et al in Maharashtra, India where knowledge about tooth decay increased and was statistically significant. ${ }^{17}$

The knowledge about nail cutting and sanitation increase was statistically significant after health education intervention in this study $(\mathrm{p}<0.001)$. The findings were supported by the study conducted by Dongre AR et al in Maharashtra, India where knowledge about nail cutting increased significantly ${ }^{18}$, Amol R et al in Maharashtra, India increased and was statistically significant after health education intervention ${ }^{17}$, Lee A et al where the school physical environment were clean in intervention school at Hong Kong. ${ }^{14}$

In our study the correct six steps of hand washing increased significantly $(\mathrm{p}<0.001)$. The findings were similar to the study conducted by Blanton E et al in Western Kenya where the correct steps of hand washing increased significantly ${ }^{19}$, Ingole AN et al findings were also similar in Maharashtra India. ${ }^{18}$

The number of clean students increased significantly after health education intervention $(\mathrm{p}<0.001)$. Our findings were supported by the findings of Chausa $J$ where children were rated clean after intervention in Malawi. ${ }^{5}$

In the present study the proper brushing steps and oral hygiene increased significantly $(\mathrm{p}<0.05)$. The findings were similar to the studies conducted Lee A et al where tooth brushing steps increased in Hong Kong ${ }^{14}$, Ingole AN et al where oral hygiene increased significantly after health education intervention. ${ }^{20}$

The practice of nail cutting and wearing clean uniform increased significantly $(p<0.05)$. Our findings were supported by the studies conducted by Ingole AN et al in Maharashtra, India ${ }^{20}$, Amol R et al after health education intervention dirty uniform decreased and were statistically significant. ${ }^{17}$ 


\section{Conclusion}

The knowledge on personal hygiene and its constituent variables significantly increased after health education intervention. The increase in knowledge was statistically significant. The practice of personal hygiene and related factors significantly increased after health education intervention. The increase in practice was statistically significant. It concluded that the change in behavior of school children was possible if the health education intervention is properly implemented to the children.

Indeed, there is need of proper health education intervention through framework of schools to the school children, for improvement regarding personal hygiene among them, throughout the nation. Curriculum must contain the topic of personal hygiene education for healthy human resources and bright future of the nation.

\section{Acknowledgements}

We are thankful to Dr. A.S Godhi, Principal, Mr. M.D Mallapur, Statistician, Department of Community Medicine, Jawaharlal Nehru Medical College, KLE University Belgaum, Principal of the Government Urdu Primary School and all the school children who participated in the study.

\section{Conflict of Interest: NIL}

Funding: No source of funding

\section{References}

[1]. United Nation Children's Fund. Water, Sanitation and Hygiene Statistics [Internet]. 2013 [Updated 2013 May 29; cited 2013 Oct 8]. Available from hhtp://www.unicef.org/wash/index_statistics.html.

[2]. Snel M, Ganguly S, Shordt K. School Sanitation and Hygiene Education - India. Resource Book. Delft, the Netherlands, IRC International Water and Sanitation Centre (Technical Paper Series; no. 39): 2002; 21.

[3]. Fact Sheet. An overview of status of drinking water and sanitation in schools in India. United Nation Children's Fund; 2013 [cited 2013 Oct $\quad 8$. $\quad$ Available r from http://www.dise.in/Downloads/best\%20practices/An\%20overview\%20of\%20status\%20of\%20drinking\%20water\%20and\%20sanita tion\%20in\%20schools\%20in\%20India.pdf.

[4]. Oyibo PG, Basic Personal Hygiene: Knowledge and Practices among School Children Aged 6-14 Years in Abraka, Delta State, Nigeria. Continental J. Tropical Medicine. 2012; 6 (1): 5 - 11.

[5]. Chausa J. Impact of hygiene education on pupils' health in school in Lugwena, Mangpchi, Malawi [dissertation, unpublished]. University of Malawi; 2008.

[6]. Siwach M. Impact of health education program on the knowledge and practices of school children regarding personal hygiene in rural panipat. International Journal of Educational Sciences. 2009; 1(2): 115-8.

[7]. Ilika AL, Obionu CO. Personal hygiene practice and school-based health education of children in Anambra State, Nigeria. Niger Postgrad Medical J 2002; 9(2): 79-82.

[8]. Greene EL, Freeman MC, Akoko D, Saboori S, Moe C, Rheingans R. Impact of a School-Based Hygiene Promotion and Sanitation Intervention on Pupil Hand Contamination in Western Kenya: A Cluster Randomized Trial. Am J Trop Med Hyg. 2012 Sept; 87(3): 385-393.

[9]. Schmidt WP, Wloch C, Biran A, Curtis V, Mangtani P. Formative research on the feasibility of hygiene interventions for influenza control in UK primary schools. BMC Public Health. 2009 Oct; 9:390.

[10]. White C, Kolble R, Carison R, Lipson N, Dolan M, Ali Y, et al. The effect of hand hygiene on illness rate among students in university residence halls. Am J of Control. 2003 Oct; 31(6): 64-70.

[11]. Aiello AE, Murray GF, Perez V, Coulborn RM, Davis BM, Uddin M, et al. Mask Use, Hand Hygiene, and Seasonal Influenza- Like Illness among Young Adults: A Randomized Intervention Trial. The Journal of Infectious Diseases. 2010; 201:491-8.

[12]. Reilly CE, Freeman MC, Ravani M, Migele J, Mwaki A, Avalo M, et al. The impact of a school-based safe water and hygiene programme on knowledge and practices of students and their parents: Nyanza Province, Western Kenya 2006. J Epidemiol Infet. 2008 Jan; 136(1):80-91.

[13]. Riaz M, Khan F. Beyond Traditional KAP Surveys-Need for Addressing Other Determinants of Behavioral Change for More Effective Hygiene Promotion. Proceedings of South Asia Hygiene Practitioners, Workshop; 2010 Feb; Dhaka, Bangladesh.

[14]. Lee A, Wong CSM, Keunq MWV, Yuen SKH, Cheng H, Mok J. Can the concept of Health Promoting Schools help to improve students' health knowledge and practices to combat the challenge of communicable diseases: Case study in Hong Kong. BMC Public Health. 2008; 8: 42.

[15]. Siwach M. Impact of health education program on the knowledge and practices of school children regarding personal hygiene in rural panipat. International Journal of Educational Sciences. 2009; 1(2): 115-8.

[16]. Dongre AR, Deshmukh PR, Garg BS. The impact of school health education program on personal hygiene and related morbidities in school children of wardha district. Indian Journal of Community Medicine, 2006; 31(1): 81-82.

[17]. Donger AR, Deshmukh PR, Garg BS. Health-promoting school initiative in Ashram schools of Wardha District. Natl Med J India. 2011; 24:140-3.

[18]. Boratne AV, Deshmukh PR, Dongre AR, Garg BS, Thaware P. An approach to hygiene education among rural Indian school going children. Online J of Health Allied Scs. 2007; 4:2.

[19]. Blanton E, Ombeki S, Oluoch OG , Mwaki A, Wannemuehler K, Quick R. Evaluation of the Role of School Children in the Promotion of Point-of-Use Water Treatment and Handwashing in Schools and Households-Nyanza Province, Western Kenya, 2007. Journal of Trop. Med. Hyg. 2010; 82(4): 664-671.

[20]. Ingole AN, Maliye CH, Bharambe MS, Mehendale AM, Garg BS. The effect of participatory school health promotion model on knowledge and practices of rural school children of Wardha, Maharashtra. J Community Med Health Educ. 2012; 2:9. 